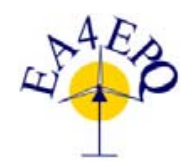

International Conference on Renewable Energies and Power Quality (ICREPQ'17)

Malaga (Spain), $4^{\text {th }}$ to $6^{\text {th }}$ April, 2017

Renewable Energy and Pamer Quality. Gournal (RE\&PQJ)

ISSN 2172-038 X, No.15 April 2017

\title{
Optimisation of bipolar plate through computational fluid dynamic simulation and modelling using nickle open pore cellular foam material
}

\author{
Tabbi Wilberforce ${ }^{1}$, Ahmed Al Makky ${ }^{1}$, A. Baroutaji ${ }^{2}$, Rubal Sambi ${ }^{1}$, A. G. Olabi ${ }^{1}$ \\ 1.Institute of Engineering and Energy Technologies, University of the West of Scotland, United Kingdom \\ 2. Cork Institute of Technology, Department of Process, Energy and Transport Engineering, UK
}

\begin{abstract}
Bipolar plates remain one of the key components in PEM fuel cells. It serves as the medium (Channel) in which the reactive substances (Hydrogen and oxygen/air) finally converge on the catalyst layer where the electrochemical reaction leading to the release of electron (electricity) occurs. Its optimization would eventually have an immense impact on the performance of the fuel cell. Simulation and modelling is a key tool in the engineering industry as it saves engineers time and money before the manufacturing of any engineering product. It helps manufacturers have firsthand information about the design feasibility before the manufacturing process in a workshop.This paper reports the modelling and simulation of the bipolar plate in fuel cell using nickel Open Pore Cellular Foam material through computational fluid dynamics software (Ansys CFX). The modelled bipolar plate was validated through design of experiments (DOE) in Ansys and compared with other flow plate design (serpentine) in the fuel cell industry.
\end{abstract}

Key words: Bipolar plate, Open Pore Cellular Foam Material, Design of Experiments, PEM Fuel

\section{Introduction}

Proton Exchange Membrane (PEM) fuel cells are promising source of power for all types of portable and stationary power applications. PEM fuel cell operates at low temperature and utilizes a solid polymer in the form of a solid phase proton conducting membrane as its electrolyte. PEM fuel cells have many advantages over the other fuel cell types; including low temperature operation, high power density, fast start up, system robustness and reduced sealing, corrosion, shielding or leaking concerns [1]. Fig. 1 depicts some basic components of PEM fuel cells. Hydrogen gas and oxygen is first introduced to the cell using the bipolar plate as its first point of contact to the PEM fuel cell before being transferred to the reactive site on the MEA through flow channels [2]. Electrochemical reactions between the hydrogen and oxygen occurs on the carbon supported platinum catalyst layer leading to the release of electrons [3]. The fuel cell upon being connected to any load with the help of current collectors allows the free electrons to travel through the load or external circuit creating electricity [4,5]. It is worth noting that the hydrogen gas on reaching the catalyst layer split into two main ions (Protons and electrons). Whiles the electrons travel through the external circuit, the protons continue its journey through the MEA as the Membrane electrode assembly only allows the flow of protons through it $[6-10]$. The positively charge protons eventually reaches the cathode region of the Fuel cell and reacts with the oxygen to form water [11]. This contributes to the environmentally friendly nature of PEM fuel cells as their byproduct is usually water [12]. Most air breathing PEM fuel cells have fans attached to the fuel cell to aid in mass transport, cooling and sometimes expel excess water from the fuel cell $[13,14]$. The gas or fuel is often humidified to help the fuel cell perform at its full potential. This humidification process is also carried out to prevent the MEA region closer to the anode side of the fuel cell from drying up [15-17]. All these processes are performed to help improve the efficiency of the fuel cell.

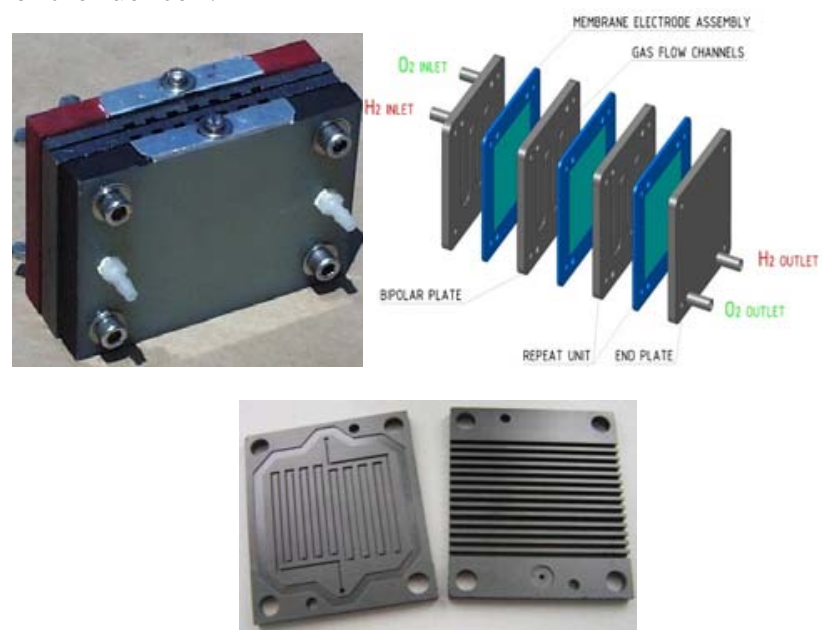

Fig 1: Proton Exchange Membrane fuel cell with five (5) stacks

It also attest to the fact that maintaining a good amount of water level in the fuel cell is very crucial and vital. A decrease or increase in the water of the fuel cell might have serious effect on its performance. Flooding of the cell occurs when the by product(Water) of the entire electrochemical reaction is not able to leave the cell $[17,18]$. This also shows how important optimisation of the bipolar plate will literally affect 
most of the physical parameters in the fuel cell. The Membrane Electrode Assembly and Bipolar plates therefore remains the main pivotal point to determine the general operation of the cell. With the bipolar plate as transfer medium of the gases, the MEA function as the bedrock for the occurrence of the electrochemical reaction [19].Efficient distribution of fuel and the oxidant to the catalyst layer can increase the use of the catalyst on the MEA, improve the management of water throug the cell and give the best collection of produce currents [19]. The MEA is composed of the Proton Exchange Membrane, an electrically conductive porous Gas diffusion layer (GDL) and an electro - catalyst layer sandwiched between two flow plates. Graphite in mordern times has been the oftenly used material for bipolar plates accounting for nearly $70 \%$ of the volume and weight of the fuel cell stack. The cost of the fuel cell is also dependent on flow plate as it forms nearly $40 \%$ of the total cost of the fuel cell [19, 20]. For good distribution of the reactants evenly and efficiently utilise the MEA, flow channels are usually machined on the surface of the bipolar plates. These channels could be parallel, serpentine, pins, straight or intergitated. Studies by researchers in recent times have proven that the flow field design has an immense impact on the cell performance. In conventional flow plates, the flow behaviour of oxygen and hydrogen inside the fuel cell and through the flow plates can effectively be predicted and analysed by the use of computational fluid dynamics (CFD) modelling tool. Many researchers employed using CFD tool in their studies to develop and optimize the bipolar flow plates. Detailed information about the flow regime is provided by the cfd simulations such as flow distribution, pressure pattern and pressure drop [21, 22].

Nickle as a metal has high melting point of around $1453{ }^{\circ} \mathrm{C}$ and generally able to resist corrosion and oxidation. It is also magnetic at room temperature and often forms alloys with other metals like Nichrome (Alloy of nickel and chromium). It is also very ductile and can be deposited by electroplating. Nickle can also be said to have catalytic properties [22]. All these material properties of the nickle Open Pore celluar foam material will eventually affects the general performance of the fuel cell either by increasing the pressure drop, temperature difference between the inlet and outlet and finally the flow rate of the gas in the fuel cell.

\section{MODELLING AND SIMULATION}

CFD programs are built to predict accurately the flow patterns and regimes, velocity analysis and pressure results in parts of the fuel cell components or through full flow plates and flow fields. The flow plates were designed to cover an active area of $25 \mathrm{~cm}^{2}$. This is basically the active area being used by the fuel cell. Some primary issues which often must be addressed before the designing of a fuel cell bipolar plate channel layout are the pressure distribution on the GDL and membrane, maintained reactant concentration over the whole active area of the GDL and membrane, membrane hydration and mitigation of flooding.

\section{SIMULATION PARAMETERS}

The simulation was done in stages as shown in fig 2 for the various designs but the meshing parameters was kept constant throughout the entire simulation process. The relevance was set at 63 and the sizing was kept on the Proximity and Curvature on the meshing drop down menu. A coarse option was also selected for the relevant centre, smoothing was medium and transition, slow. The meshing statistics showed 16,2345 Nodes and 82,105 elements.

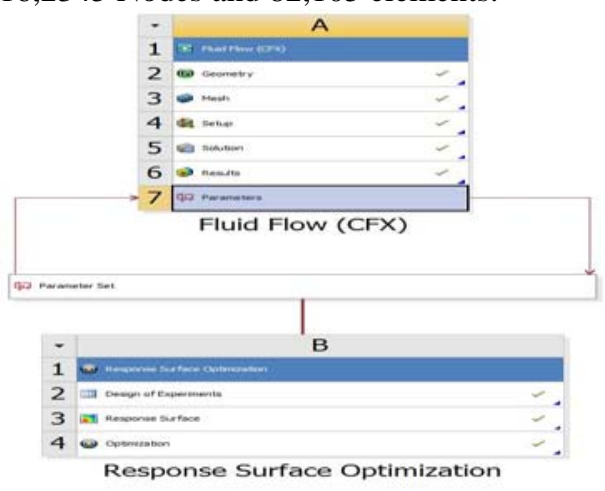

Fig 2. Various stages in the simulation process

The simulation settings were done by first writing an expression for the velocity of the hydrogen and varying the velocity over a range of values $\left(10-50 \mathrm{~ms}^{-1}\right)$ as shown in Fig. 3 and Fig. 4 . These values eventually became the set points for the running of the Design of Experiment. Again, the domain type was change to a porous domain and the rest of the parameters kept constant as shown in Fig. 3. Laminar option was selected for the fluid model and a porosity of 0.93 was selected. An interfacial area density of 0.50 and Heat transfer coefficient of 0.01 was also selected before finally running a solution for the input data. The results were then ascertained through the selection of a plane in the xy direction and various variables were selected to see their effect on the chosen plane.

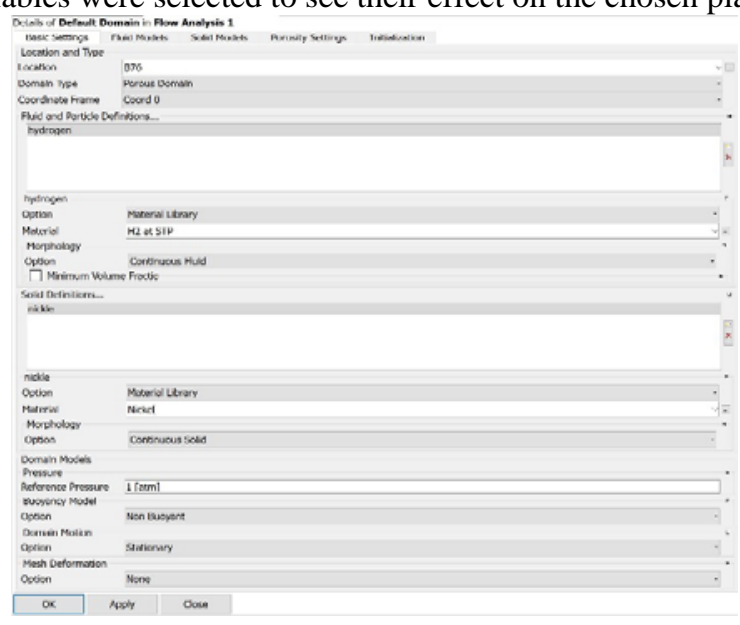

Fig. 3. Input Parameters for the various designs in settings 


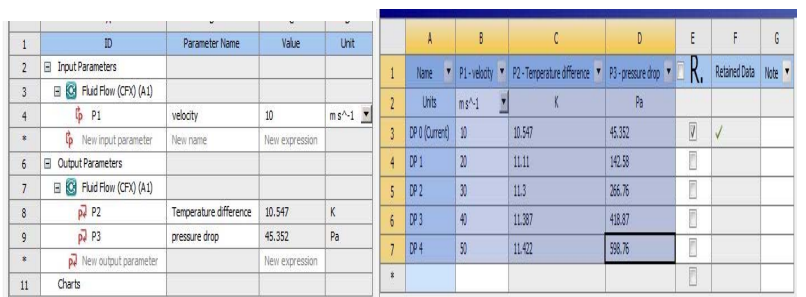

Fig. 4. Set Points for the various designs in settings.

An expression for the pressure drop and temperature difference was keyed into the software and later selected as a workbench output parameter. The Design Exploration package in ansys was then used as it contained tools for the optimization of the various designs. The response surface optimization package was chosen and design of experiment simulation was run for all the various flow plate designs.

\section{THE PROPOSED DESIGNS}

The designs were carefully selected to cover the possible direction of travel of the various gas through the flow plate which indicate the region on the MEA that would be used when the fuel cell is in operation. Some of the designs for the housing units are as below.

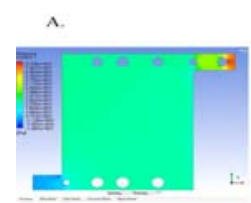

AHI

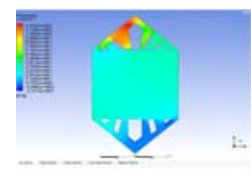

$\mathrm{AH} 4$

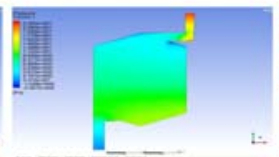

Ан2

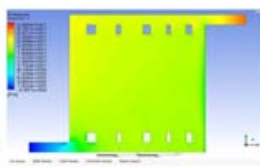

AHs

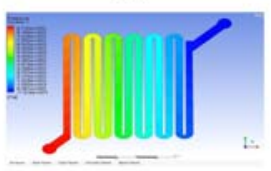

AH7
Fig 5. Anode Housing Design

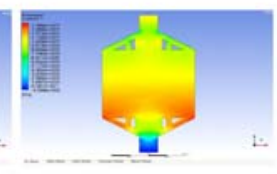

Ан 3

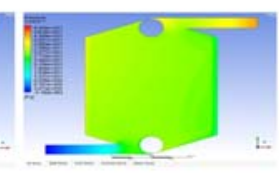

AH6

\section{SIMULATION RESULTS AND DISCUSSION}

\section{A. Anode Housing Design 1}

The first design comes with five circular holes with different diameters created at the top and bottom region of the foam. The first hole cited at the entrance of the inlet region reduces the velocity of the gas (fuel) before it circulates on the foam. The speed of the fluid is reduced further by the other circular holes right behind the first one. This often leads to the formation of convective flow through the porous region. Fig. 6 shows the pressure, velocity and velocity vector distribution of anode housing one. The pressure distribution shown in figure 6(a) shows that the pressure at the inlet is very high at $77 \mathrm{~Pa}$ but eventually reduces to $(3 \mathrm{~Pa})$ as the gas travel on the foam to the exit of the cell.

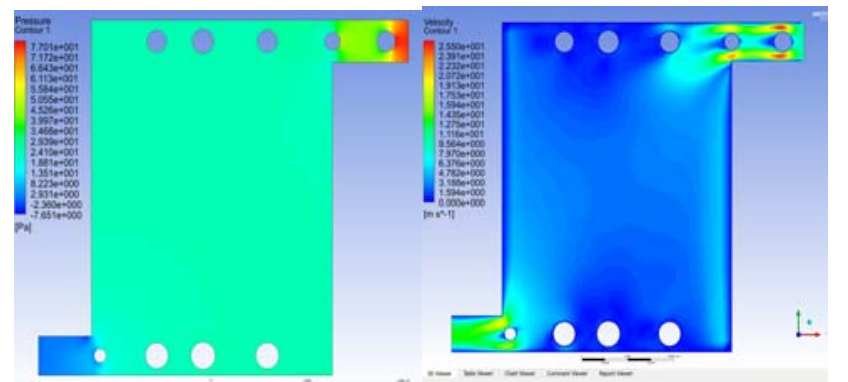

Fig 6. Numerical simulation results of AH1: (a) - Pressure drop (b) Velocity

It can further be concluded that pressure from the inlet to the outlet decreases consistently. This phenomenon eventually will affect the mass transport and general performance of the fuel cell. The pressure is also evenly distributed on the Anode housing one (AH1). Fig. $6 \mathrm{~b}$ also shows an even distribution of the velocity of the fuel through the flow plate. This velocity ensures that most part of the MEA is supplied with the gas (Hydrogen or air). The continues flow of the fluid at a constant velocity would help any water blocked in the pores of the foam to be transported to the outlet but the fluid flow is confined by channels and this leads to low flow regions being created on the left or right. Often dead zones in blue shown on fig. 6 are created. The blue regions shows areas on the Foam where there could be the possibility of accumulation of water hence reducing the efficiency of the fuel cell.

\section{B. Anode Housing Design 2}

The second design has both the inlet and outlet aligned diagonally to each other. The inlet channel has a bend towards the porous fluid domain. This reduces the velocity at which the gas may be travelling but the gas eventually spreads over the entire surface area of the Open poer cellular foam material. Just as explained in AH1, this design shows high inlet pressure in Fig. 7a but low output pressure in the existing channels. The pressure as seen in Fig. 7a is also evenly distributed in the mid-section of the design. The mid-section is the region where the membrane electrode assembly (MEA) will be placed when assembling the fuel cell.

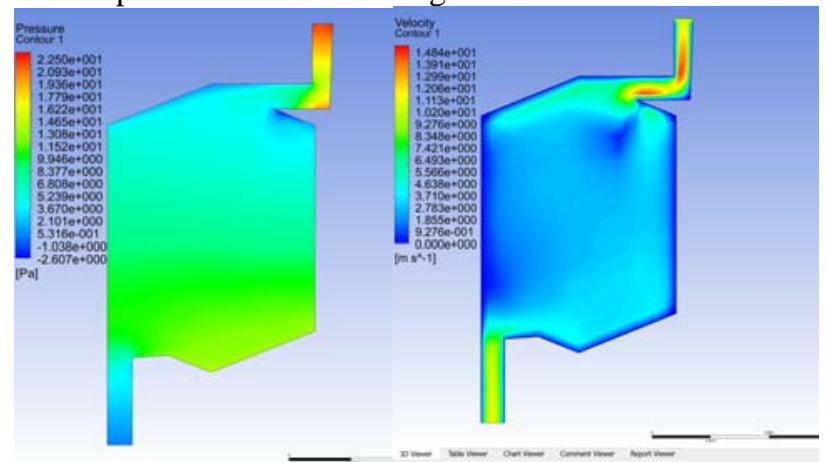

Fig 7. Numerical simulation results of AH2: (a) - Pressure drop (b) Velocity

The inlet pressure of AH1 is bigger than that of AH2. The pressure drop from the inlet to the outlet clearly explains the possibility of the fuel cell being less efficient due to the effect it might have on mass transport. The velocity distribution 
profile shown in Fig. 7b shows that a larger portion of the MEA will be utilized. Fig. 7 also indicates area where there could be likely formation of water often represented by the blue region. The blue regions in AH2 are less in area compared to that of AH1. Most blue regions for AH2 could be seen around the edges which could lead to the creation of bubbles and eventually a reduction in the fuel cell efficiency.

\section{Anode Housing Design 3}

The anode housing design 3 has the inlet and outlet aligned symmetrically towards the centre of the fluid domain. The gas after entering the fluid domain from the inlet is met by double obstruction on both the left and right side of the fluid domain. From fig.8, the mid-section from the inlet to the outlet has no obstruction. From fig.8(a), the pressure distribution through AH3 is high on the inlet but low on the outlet. The pressure drop through the entire fluid domain is quite better and suitable for mass transport in the fuel cell. Fig. 8b depicts the velocity profile. It is observed that there is a low velocity from the inlet when compared to the other designs as the flow travels straight with very little restrictions by the channels. It can be observed that some portions of the MEA will not be utilized as well.

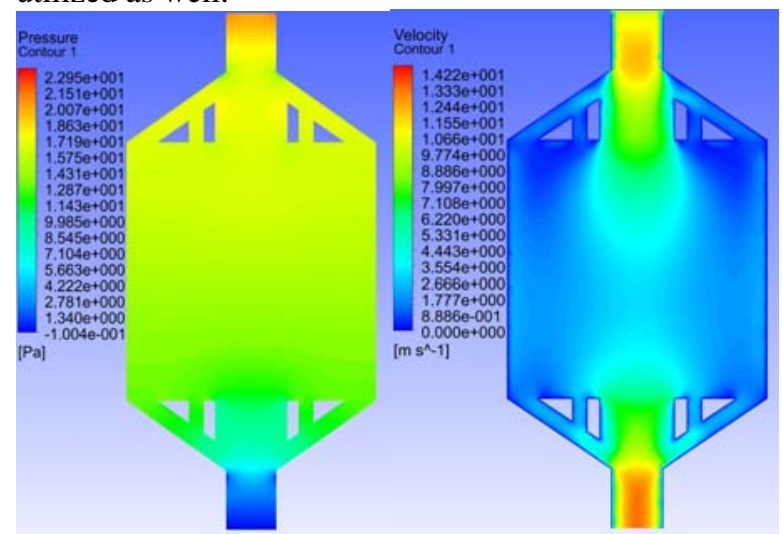

Fig 8. Numerical simulation results of AH3: (a) - Pressure drop (b) Velocity

\section{Anode Housing Design 4}

The AH4 configuration is designed as shown in figure 9. The main inlet and outlet are designed diagonally to each other. The flow is designed to spread through the channels that are also both perpendicular and diagonal to the main inlet. From Figure 9 (a), the pressure distribution is even with only a low pressure drop from the inlet to the outlet. From fig. 9 (b), an even distribution of velocity through the flow plate is noticed.

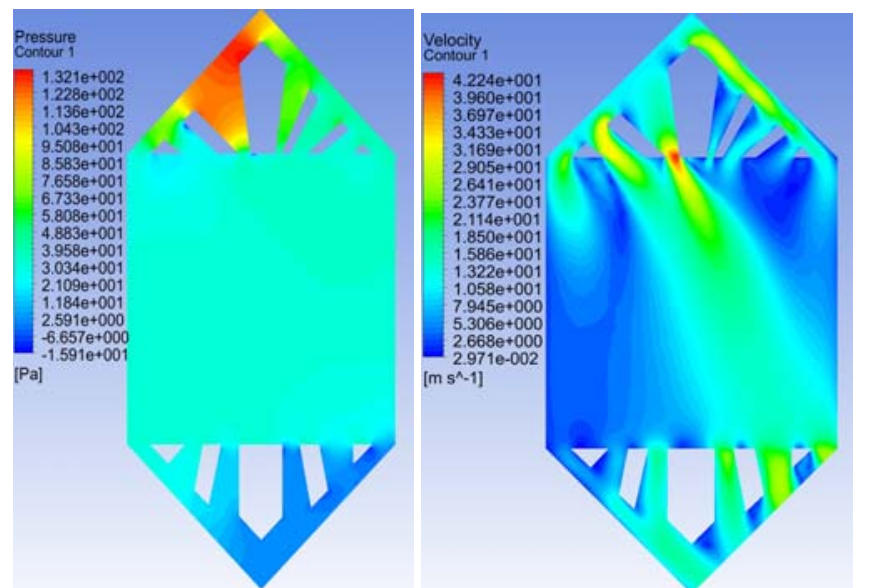

Fig 9. Numerical simulation results of AH4: (a) - Pressure drop (b) Velocity

The general design of the AH4 will greatly affect the general performance of the fuel cell. This is because the gas entering the fuel cell experiences its first obstruction diagonally and builds up momentum. This further increases its velocity but unfortunately, the obstruction will not allow the gas to flow through every region on the MEA. This also another clear situation created due to the fluid flow being confined by the channel leading to the creating of dead zones. Hence only probably one third of the MEA may be utilized. It confirms that the position of the inlet and the outlet have an immense impact on the performance or efficiency of the fuel cell.

\section{E. Anode Housing Design 5 (SELECTED DESIGN)}

The AH5 configuration is shown in Fig 10. This design was created to allow flow spread over the OPCF through many channels which are perpendicular to the main inlet channel with irregular dimensions. The downstream collector was again designed similarly to upper collector just like the AH1. This design also shows a high inlet pressure but a low out put pressure in the exiting channels.

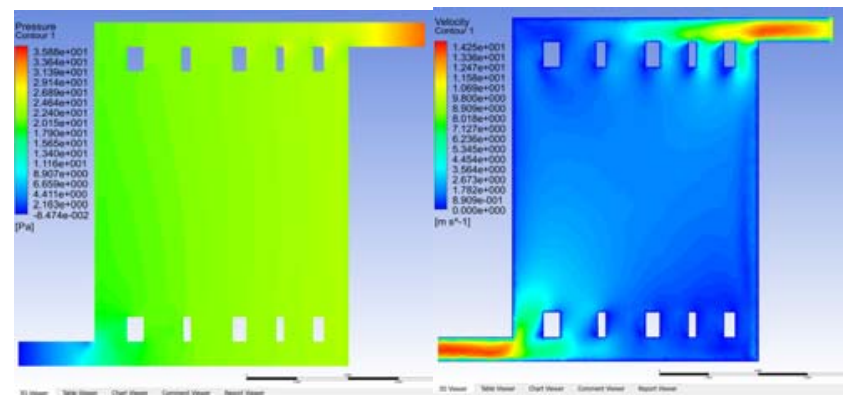

Fig 10. Numerical simulation results of AH5: (a) - Pressure drop (b) Velocity

There is also an even distribution of pressure in the mid region indicating the portion where the foam will be placed in the fuel cell. The inlet pressure for anode housing 5 is less compared to that of AH4. It shows that the pressure towards the MEA decreases from the inlet to the outlet and will also eventually affects the performance of the cell due to their 
effect on mass transport. The velocity distribution profile as shown in fig 10(b) shows that the full area of the MEA will be utilized as the gas will be able to spread over larger portion of the MEA compared to the AH4. Since the outlet velocity shown in figure 10 is higher than that of AH4, any water blockage in AH5 will be transported faster compared to that of AH4. Some low flow regions can also be seen which is equally capable of leading to the creation of dead zones and accumulation of water.

\section{F. Anode Housing Design 6}

The first thing noticed is that when the fluid coincides with the foam, their velocity increase and the fluid is diverted around the manifold channels leading to the creation of convective flow through the porous region. Fig. 3 shows the pressure distribution and velocity distribution profile for AH1. This design was created for the gas to spread over the OPFC but with an oval obstruction to decrease the velocity of the gas once it hits the oval obstruction. The downstream was designed same as the upper stream. The pressure distribution shown in fig. 11 [a] indicates that there is a high pressure on the inlet channel of (43Pa) but this decreases to a low pressure in the exiting channels $(6 \mathrm{~Pa})$.

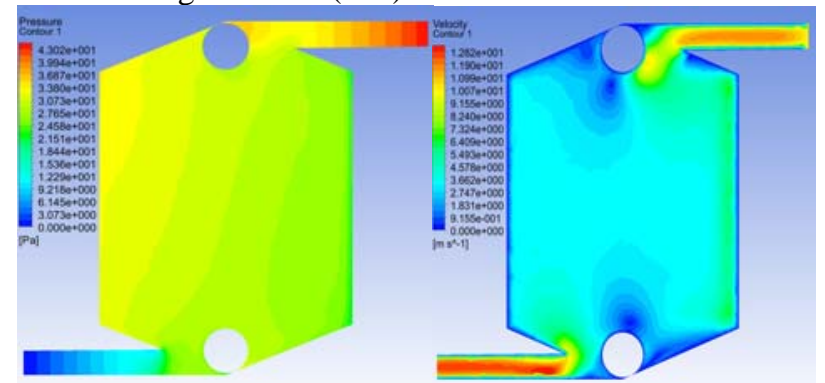

Fig 11. Numerical simulation results of AH6: (a) - Pressure drop (b) Velocity

This concludes that the pressure towards the MEA decreases from the inlet to the outlet and this may have an effect on the mass transport and the PEM fuel cell performance. It can also be observed that the pressure in anode housing 1 is evenly distributed. Figure 11b also shows an even distribution of velocity through the flow plate. The velocity ensures that the full area of the MEA is supplied with the gas (Hydrogen or air). The continuity of the fluid from the inlet to the outlet would help the blockage of water to be transported to the outlet but the fluid flow is confined by channels and this can lead equally lead to low flow regions being created on the left or right.

\section{G. Anode Housing Design 7 (SERPENTINE FLOW PLATE)}

This design supports the flow of the gas through almost all the entire surface of the MEA. From the simulation results in Fig. 12(a), it is observed that there is high inlet pressure on the first inlet channels. This pressure gradually drops from the inlet to the outlet, a clear indication that the pressure towards the MEA decreases from inlet to the outlet. The mass transport and general performance of the fuel cell is highly affected as a result of this physical characteristics occurring in the PEM fuel cell. Figure 12(b) also shows that there is an even distribution of the velocity of the fluid (hydrogen and air) through the entire flow plate. The velocity supports the full area of the MEA being supplied with the gas (hydrogen or air). The serpentine flow plate design ensures a constant flow of the fluid through the channels and this in effect removes any excess fluid that may remain in the fuel cell. Again, this design removes any water that may block the channels to the outlet easily. The boundary layers of lower velocity fluid flow are observed at the channel edges. This often leads to water channels being moved to the channel walls creating annular flow. The blue regions on the pressure simulation shown in figure 12(a) indicates region of possible dead zones. This indicates areas around the flow channel where the gas might not flow through.

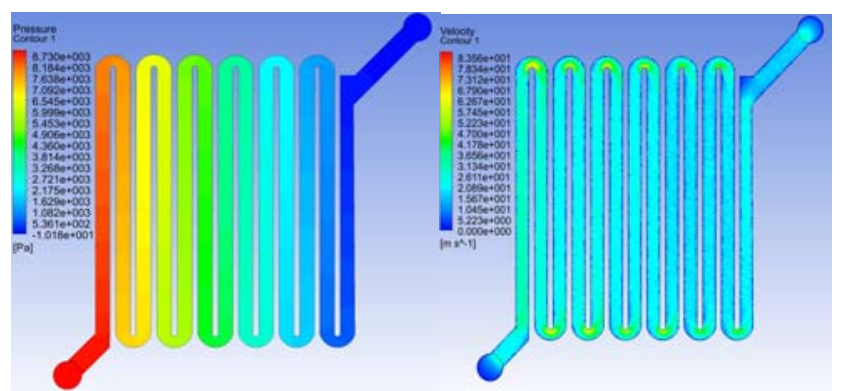

Fig 12. Numerical simulation results of AH7: (a) - Pressure drop (b) Velocity

\section{VALIDATION OF SIMULATION RESULTS}

Through design of Experiments (DOE) in Ansys simulation software, an indebt simulation was performed using some selected velocities as set points $[10-50 \mathrm{~m} / \mathrm{s}]$ against the possible pressure drop likely to be experience in real life situations. Each of the design showed some pressure drop when the velocity was varied from the highest to the lowest but the pressure drop seen when using the serpentine flow plate design on the market was far greater. Figures $13-20$ shows the various plots for each anode housing designs.

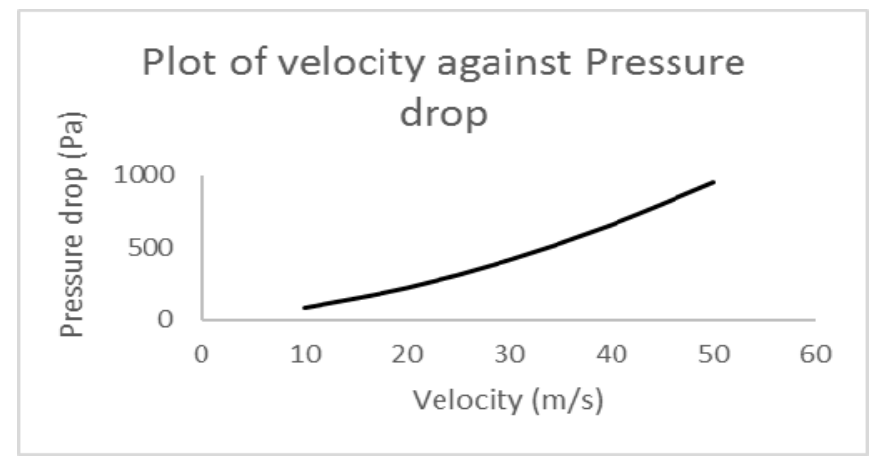

Figure 13: Graph of Velocity against pressure drop for AH1 


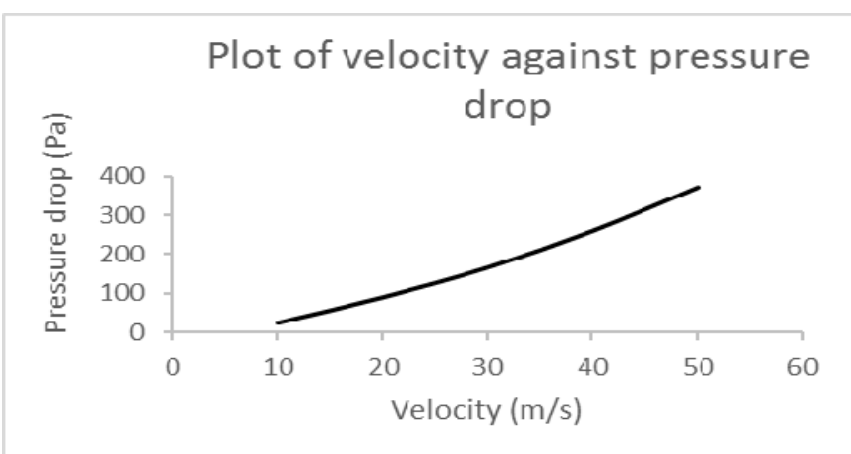

Figure 14: Graph of Velocity against pressure drop for AH2

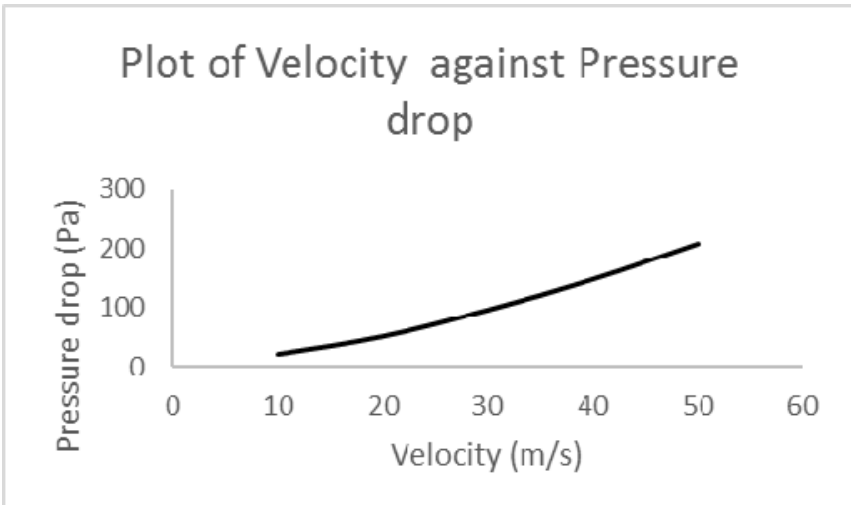

Figure 15: Graph of Velocity against pressure drop AH3

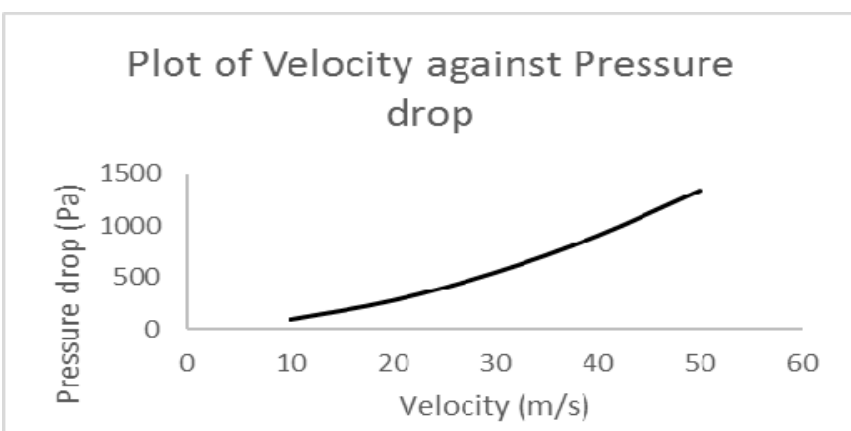

Figure 16: Graph of Velocity against pressure drop AH4

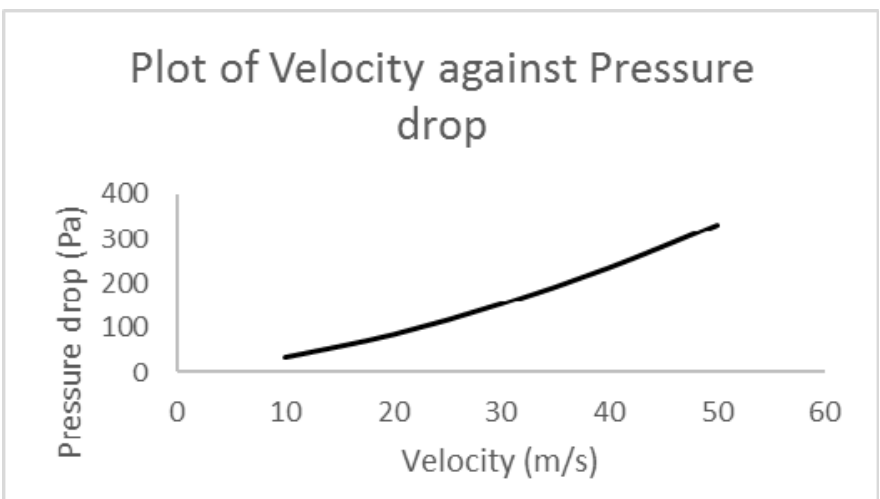

Figure 17: Graph of Velocity against pressure drop AH5

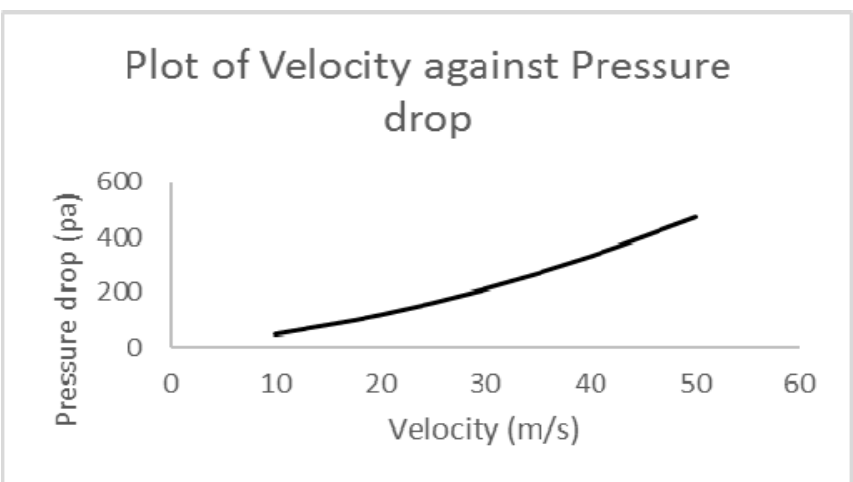

Figure 18: Graph of Velocity against pressure drop AH6

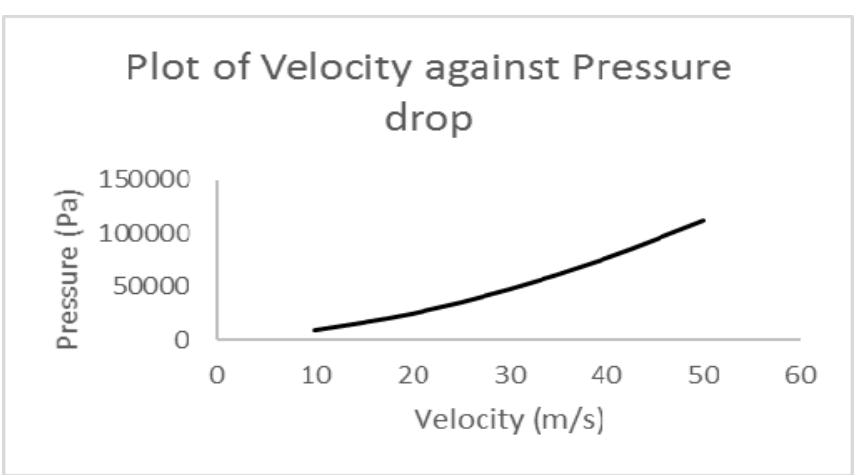

Figure 19: Graph of Velocity against pressure drop AH7

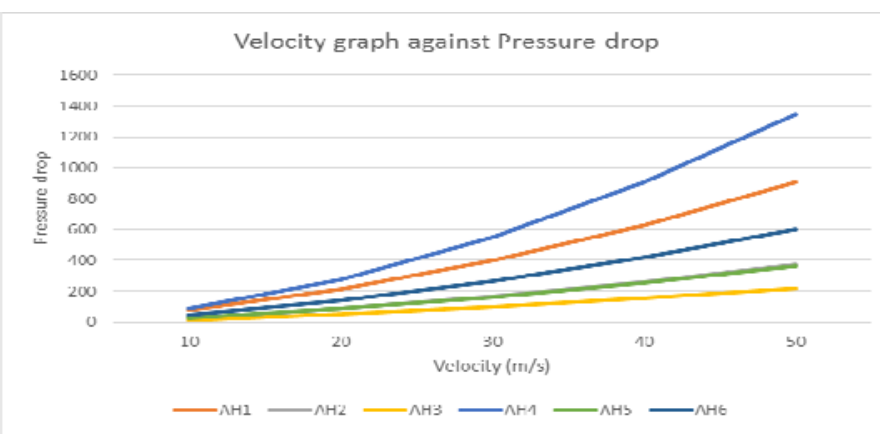

Figure 20: Graph Comparing the various types of Anode housing designs (AH 1 - AH6) in relation to Velocity rate against pressure drop and Temperature

\section{CONCLUSION}

In summary, this work eventually, exposed the parameters that affects the general performance of fuel cell and also led to the numerical analysis of five different anode housing designs using the Open Pore Cellular flow Plate Material.

It was realized that dead zones which often leads to accumulation of water in the fuel cell and hence prevents a portion of the MEA being utilized could be curbed by creating an obstruction from the inlet where the hydrogen gas is introduced before entering the membrane to divert the fuel to these likely dead zone areas. This will eventually improve the general performance of the fuel cell as greater portion of the MEA will be utilized if this approach is carefully followed in the designing process. 


\section{REFERENCES}

1. X. Li and I. Sabir, "Review of bipolar plates in PEM fuel cells: Flow-field designs”, Int J Hydrogen Energy, 30 (4), pp 359-371, 2005.

2. J.G. Carton and A.G. Olab, "Design of experiment study of the parameters that affect performance of three flow plate configurations of a proton exchange membrane fuel cell”, Energy, 35 (7), pp 2796-2806, 2010.

3. X.D. Wang, Y.Y. Duan, W.M. Yan, and X.F. Peng,” Local transport phenomena and cell performance of PEM fuel cells with various serpentine flow field designs”, Journal of Power Sources, 175(1), pp 397407, 2008.

4. A. D. Le and B. Zhou, "A generalized numerical model for liquid water in a proton exchange membrane fuel cell with interdigitated design”, J. Power Sources, 193 (2), pp 665-683, 2009.

5. J.P Kloess, X. Wang, J. Liu, Z. Shi and L. Guessous, "Investigation of bio-inspired flow channel designs for bipolar plates in proton exchange membrane fuel cells”, J.Power Sources, 188(1), pp 132-140, 2009.

6. S. U. Jeong, E.A. Cho, H. J. Kim, , T.H. Lim, I. H. Oh and S.H. Kim,” Effects of cathode open area and relative humidity on the performance of air-breathing polymer electrolyte membrane fuel cells", Journal of power sources,158(1), pp 348-353, 2006.

7. Parvanian AM, Panjepour M. "Development of Open Pore Copper Foams to Use as Bipolar Plates in Polymer Electrolyte Membrane Fuel Cell Stacks” Iranica Journal of Energy \& Environment, 4, (2): pp 99-103, 2013.

8. M. Mohammadi, G.N. Jovanovic and K.V. Sharp "Numerical study of flow uniformity and pressure characteristics within a microchannel array with triangular manifolds" Computers \& Chemical Engineering, 52, pp 134144, 2013.

9. Ma L, Warthesen S, Shores D. "Evaluation of materials for bipolar plates in PEMFCs", Journal of New Materials for Electrochemical Systems, 3,(3): pp 221-228, 2000.

10. A. Kumar and R.G. Reddy "Application of Metal Foam in the Flow-Field Distributor of Polymer Electrolyte Membrane Fuel Cell Stack”. 1060, 204th Meeting, The Electrochemical Society, Inc, 2003

11. A. Kazim, H. T. Liu and P. Forges, "Modelling of performance of PEM fuel cells with conventional and interdigitated flow fields”, J.Appl.Electrochem, 29 (12), pp 1409-1416,1999.

12. V. Lawlor, S.Griesser, G.Buchinger, A.G.Olabi, S. Cordiner and D. Meissner, "Review of the micro- tubular solid oxide fuel cell: Part I. Stack design issues and research activities”, J.Power Sources,193 (2),pp 387-399, 2009.

13. A.P. Manso, F. F. Marzo, J. Barranco, X. Garikano and M.G. Mujika, "Influence of geometric parameters of the flow fields on the performance of a PEM fuel cell. A review”, International Journal of Hydrogen Energy, 37 (20), pp 15256-15287, 2012.

14. Tseng, Chung-Jen, et al. "A PEM fuel cell with metal foam as flow distributor”, Energy Conversion and Management 62, pp 14-21, 2012.

15. A. D. Le and B. Zhou, "A generalized numerical model for liquid water in a proton exchange membrane fuel cell with interdigitated design”, J. Power Sources, 193 (2), pp 665-683, 2009.

16. H. Liu, P. Li and J.V. Lew,"CFD study on flow distribution uniformity in fuel distributors having multiple structural bifurcations of flow channels”, International Journal of Hydrogen Energy, 35 (17), pp 9186-9198, 2010

17. C.J. Tsang, B.T. Tsai, Z.S. Liu, T.C. Cheng, W.C. Chang and S.K. Lo, "Effects of flow field design on the performance of a PEM fuel cell with metal foam as the flow distributor", International Journal of Hydrogen Energy, 37 (17), pp 13060-13066, 2012

18. Peavey MA. In: Fuel from water: energy independence with hydrogen. 11th ed. Louisville, KY: Merit Inc: 2003.

19. Chang HP, Chou CL, Chen Ys, Hou Ti, Weng BJ. The design and cost analysis of a portable PEMFC UPS system. International Journal on Hydrogen Energy 2007; 32:316 - 22.

20. Afsari E, Jazayeri SA. Effects of the cell thermal behavior and water phase change on a proton exchange membrane fuel cell performance. Energy Convers Manage 2010; 51: 655 - 62

21. E. Hontanon, M. J. Escudero, C. Bautista, P. L. GarciaYbarra, and L. Daza, "Optimisation of flowfield in polymer electrolyte membrane fuel cells using computational fluid dynamics techniques." Journal of Power Sources, 86(1), pp 363368, 2000.

22. S. K. Dong, B. T. Yun and D. K. Lee, "Design and numerical study for $\mathrm{l} \mathrm{kW}$ tubular SOFC APU system”, Anonymous Fuel Cell Seminar, San Antonio; TX; United states: Electrochemical Society, Inc, October, pp- 701-706, 2007. 